\title{
Samuel W. Bloom e a História da Sociologia Médica
}

\author{
EVERARDO DUARTE NUNES •
}

\author{
BLOOM, Samuel W. \\ Word as Scalpel: a History of Medical Sociology. \\ New York: Oxford University Press, 2002.
}

\section{Introdução}

Outras histórias da trajetória da sociologia médica serão escritas, mas seguramente, nenhuma poderá deixar de mencionar e mesmo tomar como referência a que foi escrita por Samuel W. Bloom. Intitulada Word as Scalpel: a History of Medical Sociology e publicada em 2002, constitui a mais detalhada história do desenvolvimento e institucionalização da Sociologia Médica nos Estados Unidos, mostrando como esse campo de conhecimento iria se constituir em um dos mais férteis para a sociologia e para a medicina.

O livro se baseia em trabalhos publicados em sociologia médica, entrevistas com importantes figuras do campo e na própria trajetória do autor, que, ao contar a história da área, nos conduz para o conhecimento das suas experiências e pesquisas realizadas ao longo de cinco décadas. Recebida com críticas elogiosas, a obra resgata e documenta os precursores que no final do século XIX lançaram algumas idéias sobre a abordagem do social e os pioneiros das primeiras décadas do século XX, e o início de uma proposta sociológica que irá definir e criar uma estrutura institucional para a sociologia médica, partindo do célebre trabalho de Parsons, de 1951, e que se estende ao longo do século XX e chega ao século XXI.

Com este trabalho procuro resgatar essa obra, que traça um panorama da sociologia médica e da sua importância para o campo dos estudos sociológicos e aspectos da vida desse autor, cuja visão pioneira e dedicação ao campo nos encanta até hoje. 


\section{O autor}

Samuel W. Bloom nasceu na Pennsylvania, em 1921, numa família de origens judaicas, e sua opção pela Sociologia reflete essas origens, associadas aos interesses despertados pelos efeitos dos meios de comunicação, especialmente o cinema, que serão objeto de seus primeiros trabalhos (BLOOM, 1990, p. 3). Em 1953, obtém o MA, com a tese intitulada The Image of Jewry in World History: Toynbee, Spengler, and Weber, apresentada na The New School of Social Research e, em 1956, a tese para o grau de doutor, denominada A Social Psychological Study of Motion Picture Audience Behavior: A Case Study of the Negro Image in Mass Communication, na University of Wisconsin.

Em trabalho anterior (NUNES, 2003), reportei-me a esses momentos iniciais da carreira de Bloom e transcrevi o relato feito pelo próprio Bloom, quando narra que esses eram os temas com os quais ele mais se identificava:

De um lado, eu necessitava objetivar e conseguir alguma compreensão das qualidades universais de ser judeu no terrível contexto da Alemanha hitlerista e dar base às emoções de minha viagem pela Palestina em 1947. De outro lado, eu estava certo que, de alguma forma, a ciência social podia explicar-nos o que a mass media estava fazendo com a sociedade (BLOOM, 1990, p. 3).

Confessa que essas questões influenciaram fortemente seu trabalho subseqüente e que ele estruturava o seu pensamento muito mais como um psicólogo social do que como um sociólogo. Nesse sentido, "eu estava interessado na influência relativa da predisposição dos valores individuais e das normas comunitárias fortemente dominantes" (BLOOM, 1990, p. 3).

Bloom assinala que, mais tarde, iria perceber que o plano da tese permaneceu com ele por um longo período, marcando sua preocupação com o processo de socialização do adulto. Este seria um tema para o qual se voltaria mais tarde e embora a sociologia médica não fosse de seu particular interesse nos primórdios de sua carreira acadêmica, desde os anos 50 Bloom junta-se ao grupo que seria condutor das primeiras experiências com a ciência social no campo da medicina, tais como August Hollingshead (Yale University), Donald Young (Russel Sage Foundation) e George Reader (Columbia University).

Inicia o seu contato quando se tornou parte do grupo do Bureau of Applied Social Research, da Columbia University, como pesquisador, realizando observações participantes e entrevistas com estudantes de medicina. Como 
relato neste texto, é interessante o trecho de sua "autobiografia" quando diz que a fim de tentar superar as inseguranças iniciais num novo campo, pois receava perder a identidade de sociólogo, mesmo ainda como um calouro no campo e ser absorvido pela medicina, dedica-se a conhecer a história da sociologia e da medicina e à leitura de obras de ficção literária nas quais médicos estavam presentes (Tchekhov, Ibsen, Shaw).

Ainda na metade dos anos 50, participará da criação do Committee of Medical Sociology, do qual será o secretário-tesoureiro, sucedendo Robert Straus, e que será, a partir de 1959, denominado de The Medical Sociology Section, da American Sociological Association (NUNES, 2003). Definia-se para Bloom uma carreira em sociologia médica, cujo processo de desenvolvimento acompanharia ao longo de cinco décadas, testemunhando o processo de sua institucionalização, desde o início. Esse será o relato pormenorizado que irá oferecer em seu livro que desvenda todo o processo de formação e desenvolvimento do campo da sociologia médica nos Estados Unidos.

Hoje, Bloom é professor de Sociologia e Medicina Comunitária na Escola de Medicina de Mount Sinai, em New York e professor emérito de Sociologia, na City University of New York Graduate Center. Foi distinguido com o Reeder Award como sociólogo médico, em 1989, e o Certificate of Appreciation for a Career of Distinguished Service, em 1997, tendo sido membro da Robert Wood Johnson Commission on Medical Education, 1990-1992.

\section{A obra}

Embora a principal questão do livro seja analisar o período moderno na história da sociologia médica nos últimos 50 anos, o autor recupera suas origens mais remotas. Para Bloom, suas origens partilham o solo comum de três concepções: a medicina como ciência social, a saúde pública e a medicina social desenvolvidas no interior da medicina no século XIX, no momento em que a sociologia médica crescia como um campo autônomo, a partir dos marcos da própria sociologia e da psicologia social, em menor extensão. Esses aspectos são desenvolvidos na Parte I - A Sociologia Médica antes de 1940, em cinco capítulos.

Ressalta o autor que os estudos realizados a partir da segunda metade do século XIX eram episódicos e se relacionavam à luta pelos direitos políticos e sociais da classe média européia, pelas lutas da classe trabalhadora inglesa e pelas mudanças tecnológicas e sociais causadas pela Guerra Civil nos Estados Unidos. Aponta que: 
A sociologia médica, em suas origens no século XIX, é derivada da superposição desses três conceitos: a medicina como ciência social, medicina social e sociologia da medicina. Todas as três interessadas em explicar a interação entre as condições sociais e problemas médicos a idéia de que a doença humana é sempre mediada e modificada pelas atividades sociais e ambiente cultural (BLOOM, 2002, p. 11).

Wirchow e Neumann escrevem nesse momento, mas a percepção que têm da "ciência social", de caráter utilitarista e identificada com a reforma social, é totalmente diferente da que existe hoje. Esta foi também a posição que mais tarde assumiria Sigerist, entre 1920-1940, ao conceber um ambicioso projeto de "sociologia da medicina".

Neste primeiro momento, Bloom destaca os seguintes pontos: 1) o fato de que os fatores sociais em saúde tinham sido reconhecidos por médicos das mais distintas civilizações, no mínimo a partir de Hipócrates; 2) as próprias epidemias provocaram a introdução de medidas sanitárias, especialmente nas áreas urbanas; 3 ) a medicina social emergiu no século XIX como um movimento para investigar problemas à luz das ciências sociais, mas as idéias não foram além de fornecer impulso para o movimento de saúde pública na elaboração de uma infra-estrutura sanitária; 4) o principal esforço foi desenvolver uma base teórica para o programa administrativo de saúde pública; 5) o movimento do século XIX, sob a bandeira da "Medicina é uma ciência social", não alcançou seus objetivos, embora tenha sido forte o suficiente para estabelecer um diálogo com a biomedicina que emergiu da ciência bacteriológica, mas "a nova teoria do germe foi tão dominante para a medicina que o desenvolvimento de uma genuína medicina social foi abortada" (p. 22); 6) nas primeiras décadas do século XX a medicina social foi retomada, mas dominada pela biomedicina, tornou-se "pragmática e aplicada".

Para o autor, a emergência da sociologia médica somente pode ser entendida dentro do contexto da universidade norte-americana, antes de 1920. Situa que, no último quarto do século XIX, a ciência social e a medicina deram "grandes saltos", pois antes eram intelectualmente dependentes da Europa, e isto se tornou possível com a reorientação da universidade nos Estados Unidos, com sua secularização e orientação empírico-científica. Concomitante a isso, ocorre a emergência da escola médica moderna. 
Segundo Bloom (p. 24), esse é o cenário para o surgimento da sociologia médica, tanto antes como depois de sua institucionalização e "reflete as pressões da medicina, como sua profissão anfitriã e a sociologia geral, como sua disciplina matriz". Traça o desenvolvimento da sociologia, cuja entrada para a modernidade pode ser datada da criação da American Social Science Association, em 1865.

O aparecimento de associações acadêmicas profissionais ocorre no final do século XIX e início do século XX: a de História, em 1884; a de Economia, em 1885; a de Antropologia, em 1902, a de Ciência Política, em 1904 e a de Sociologia, em 1905, que se tornam "a principal fonte e expressão da ciência social nos Estados Unidos” (p. 26).

O desenvolvimento das ciências sociais ocorre num momento em que a educação médica ministrada nas 155 escolas de medicina era vista de forma bastante crítica, por sua deficiência, o que despertou a necessidade de seu estudo. Isto foi realizado em 1908/1910, por Abraham Flexner. Ao relacionar as transformações da universidade americana e a presença da sociologia, Bloom traça interessantes aspectos do desenvolvimento da sociologia e da educação médica, num momento em que ocorria intensa e ampla expansão das instituições educacionais e das características da sociologia nas primeiras décadas do século XX e das influências européias, especialmente francesas e inglesas. Ao destacar o papel das fundações, lembra que a Russell Sage Foundation foi importante no desenvolvimento da sociologia empírica e, embora houvesse esforços para trabalhar a saúde pública e a medicina social, não ocorreu nesta primeira fase da sociologia americana a identificação da sociologia da medicina como um campo de atividade intelectual institucionalizado.

$\mathrm{Na}$ sequiência de seu relato, Bloom explica que nas primeiras décadas do século XX não houve esforços na sociologia acadêmica em se criar um campo específico para os estudos de sociologia médica, cujos fundamentos se estabelecem no período entre as duas guerras mundiais. De um lado, Bernhard Stern, Michael Davis e Henry Sigerist, dentro de suas tradições da medicina social e, de outro, Lawrence Henderson usando a medicina como um caso ilustrativo para o desenvolvimento da teoria social e abrindo caminho para Parsons e Merton na construção do funcionalismo e sua vertente estrutural.

Essas décadas assistiram ao desenvolvimento da psiquiatria social e da ecologia social da doença. Foram atividades altamente produtivas, mas dentro de um padrão acadêmico de trabalho individual, realizadas por médicos e sociólogos, mas não representaram um trabalho contínuo e institucionalizado. 
Mesmo com muitas atividades durante o período, Bloom assinala que a sociologia médica foi parte de um desenvolvimento no campo da pesquisa que envolvia problemas sociais, incluindo as questões de saúde e doença (Ogburn, Sydenstricker, Michael Davis), mas não se apresentou como uma subespecialidade propriamente dita: a maior parte dos estudiosos tinha origem na saúde pública e na medicina social. Se, de um lado, a sociologia médica ira se estabelecer no pós-Segunda Guerra, um desenvolvimento intelectual importante, paralelo a este, será o da sociologia nas universidades de Chicago, Harvard e Yale. Nesse sentido, Bloom recupera, em um denso capítulo, a atração exercida pela Universidade de Chicago e o momento em que dois jovens graduados, Robert E. L. Faris e H. Warren Dunhan, guiados por Ernest W. Burgess, ao testarem modelos teóricos e de pesquisa elaboram os estudos pioneiros sobre doença mental em áreas urbanas. Além de testar a hipótese sobre as relações entre industrialização/urbanização-doença mental, havia a evidência do aumento das taxas de crime e delinqüência, que foi interpretado como sendo "tipos similares de desvio, diferentes, mas dentro do mesmo continuum básico, comum da doença mental” (p. 69).

Acrescente-se, ainda, que a doença mental era vista no plano das normas sociais e da patologia social. Mesmo com as controvérsias sobre a distribuição das doenças mentais nas áreas urbanas e rurais, o estudo de Faris e Dunhan sobre a urbanização colocou este tema como importante nos estudos epidemiológicos e lançou importantes questões sobre a etiologia social da doença mental.

A essas questões viriam se associar aquelas referentes às relações interpessoais nas situações terapêuticas que, segundo Bloom, se tornaram a fonte de um segundo antecedente de relevância para a sociologia médica, especialmente as desenvolvidas pelo psiquiatra Harry Stack Sullivan (18921949). Este será o período de formação da sociologia médica do qual não se pode isolar a presença de duas figuras que lideram seu desenvolvimento intelectual: Lawrence J. Henderson (1878-1942) e Bernhard J. Stern (18941956). Bloom (1990b), que já havia escrito de forma detalhada a vida e a carreira de Stern, retoma nesse livro a figura deste pioneiro da sociologia médica, tido como um radical, esquecido por muitos, mas cujo legado intelectual é inconteste, ao passo que Henderson foi atacado como reacionário (p. 103).

De maneira geral, por volta dos anos 1940 estava completado o quadro que deu origem à sociologia médica, ou seja, "a subestrutura da identidade 
cognitiva da disciplina" estava estabelecida. E a Segunda Guerra, com as interrupções que ocasionou, foi também um estímulo e "tornou-se o ponto marcante para a história da sociologia médica" (p. 108).

A partir desse momento, abria-se o largo período de consolidação da sociologia médica, que se estenderia até 1980. A emergência desse campo não foi sem obstáculos: "A estreita ligação com a saúde pública e medicina preventiva, por exemplo, que tinha sido tão promissora entre as guerras, foi solapada pela reação pós-guerra contra uma 'medicina social' que era confundida com "medicina socializada" (p. 114). Data desse momento um deslocamento na academia para as "ciências básicas do comportamento" e psiquiatria, inclusive como parte do ensino. Bloom explica que as relações entre psiquiatria e ciências sociais foram melhores pelo fato de que não havia, como no caso da medicina social, questões políticas a serem debatidas, e o interesse se focalizou na pesquisa.

Ao analisar a primeira fase da sociologia médica no pós-guerra, Bloom assinala a importância das universidades no período de 1945 a 1960, desfilando os pesquisadores que iriam escrever a história desse campo a partir dessa data: em Yale - Robert Straus e Jerome Myers; em Harvard - Mark Field e Renée Fox; em Columbia - Patrícia Kendall e Mary Goss, em Chicago - Eliot Freidson, Blanche Geer, Howard Becker e Rue Bucher. Todos estavam iniciando suas pesquisas e nenhum havia recebido treinamento formal em sociologia médica, pois somente em 1955 é que foi estabelecido em Yale tal treinamento em nível de pós-graduação.

Desenvolvendo seus trabalhos com características próprias, essas universidades estabeleceram fortes laços entre elas e, sem dúvida, o contexto da história do pós-guerra foi importante fator na caracterização dessas contribuições, que, além disso, trouxeram as peculiaridades de seus personagens com suas biografias. Bloom destaca o papel da Universidade de Yale até 1950 nos programas de sociologia médica como uma subespecialidade, que continuou na década seguinte, embora agora apareça um outro tipo de instituição, o National Institute of Mental Health (NIMH), criado pelo Congresso americano em 1946.

Destaca-se o papel do médico Robert Felix, seu primeiro diretor, de 1949 a 1964, que atribuiu aos sociólogos e à sociologia parte vital nessa instituição e que Bloom considera uma das principais figuras no desenvolvimento da sociologia médica. Se, de um lado, foi importante o papel de um órgão federal, de outro, não se pode descartar o que foi feito pelas instituições privadas. Dentre 
elas, a Russell Sage Foundation, que desempenhou papel relevante na criação da primeira organização profissional de sociólogos médicos (Committee on Medical Sociology, posteriormente transformado na Section on Medical Sociology da ASA) e que, no caso de Bloom, patrocinou materiais de ensino e a publicação do livro The doctor and his patient: a sociological interpretation, em 1963 (BLOOM, 1963). Trata-se do relato de uma das possibilidades de abordar as ciências sociais no trato do relacionamento médico-paciente (NUNES, 2003).

Na questão dos estudos que mais tarde seriam parte integrante de uma sociologia da educação médica, em 1952, destaca-se a Commonwealth Fund, com pesquisas cujo tema foi a socialização profissional e o processo de formação médica. Ressalte-se, ainda, outra fundação, The Milbank Memorial Fund, que tomou as ciências sociais como foco de atenção e estendeu sua área de atuação para a América Latina, enfatizando a questão da educação médica.

Segundo Bloom, o período que vai de 1955 a 1980, duas décadas e meia, foi de intenso crescimento profissional (2002, p. 243) e da presença das associações, em especial a Section on Medical Sociology, que foi presidida pelos mais ilustres sociólogos médicos e tinha como objetivo:

promover o desenvolvimento das ciências do comportamento em medicina
através do intercâmbio organizado de idéias, experiências de ensino e programas
e resultados de pesquisas [...] definindo a 'sociologia médica' em seu sentido
mais amplo e aplicando os conceitos da sociologia, antropologia e psicologia
social aos problemas da saúde e da doença (BLOOM, 2002, p. 236).

A importância da Seção dentro da ASA pode ser vista pelo número de associados ( 7 a $8 \%$ de todos os membros da Associação) e pela publicação de um periódico (desde 1966) dedicado exclusivamente à saúde - The Journal of Health and Social Behavior -, além de anualmente conceder o prêmio L G. Reeder ao sociólogo da medicina que mais se distinguiu no período, incluindo o conjunto de sua obra.

$\mathrm{Na}$ análise de Bloom, o período atual (de 1980 a 2000) pode ser denominado de "Uma era de mudança". Retomando pontos apresentados, o autor situa que, a partir de 1945, o desenvolvimento da pesquisa em sociologia médica foi rápido e diversificado, guiado por fortes líderes, intensificando as relações entre medicina e ciência social. Considera que a primeira metade desse período foi dominada por diversas questões, especialmente relacionadas ao campo da epidemiologia social, na construção de uma teoria da psicologia 
social das relações interpessoais nas instituições terapêuticas e pelas análises no campo da sociologia das profissões. A segunda metade, a partir dos anos 70, focalizou as explicações socioeconômicas e sociopolíticas, oferta dos serviços de saúde e da organização das instituições de cuidados à saúde. Sob certos aspectos, as "ciências sociais retornavam às velhas batalhas de trinta anos atrás" (p. 251). Para o sociólogo, a sua própria interpretação é que "em sociologia médica, o produto intelectual das duas primeiras décadas seguintes à guerra foi principalmente em pesquisa básica" e fatos como o Sputinik russo, em 1957, provocaram uma corrida para acelerar a formação científica, com forte empenho orçamentário do governo. Isto não impediu que se voltasse a discutir se a ciência social era uma ciência "real" e qual era a sua "utilidade".

Ao situar os momentos mais recentes, lembra que nos anos 80 a sociologia médica estava no auge de seu desenvolvimento - sociólogos estavam nas faculdades de medicina em tempo integral ou parcial: dos 228 departamentos de sociologia com cursos de pós-graduação, 226 estavam oferecendo especialização em sociologia médica e cientistas sociais ocupavam posições em organizações governamentais de pesquisas. Para o autor, a partir dessa data, o ambiente para a sociologia e sociologia médica começou a mudar, incluindo cortes nos orçamentos; no entanto, as "behavioral sciences" tornaram-se preferidas nos documentos oficiais. Quanto à sociologia médica, das suas origens nos departamentos de sociologia, nos anos 50, foi passando para o campo das ciências pré-clínicas das faculdades de medicina. Entende que "as tendências institucionais da sociologia médica só podem ser entendidas contra o pano de fundo da sociologia e da medicina como profissões acadêmicas e dentro do contexto das mudanças históricas de ambas as profissões e do sistema de cuidado à saúde" (p. 273).

\section{Post scriptum}

Em 2004, Samuel W. Bloom ganhou o Eliot Freidson Outstanding Publication Award, por seu livro. Em realidade, esse alentado trabalho de reconstituição histórica pode ser visto como exemplar para o estudo de um campo do conhecimento. Seu título revela o caminho que o autor quis dar ao conteúdo do seu livro e as influências recebidas Como escreve na introdução, o título Word as scalpel: a history of medical sociology testemunha a influência da advertência de Lawrence J. Henderson: "A doctor can damage a patient as much with a misplaced word as with a slip of the scalpel". (p. 8). Como 
pergunta Bloom, se as palavras são tão poderosas para ferir, quão potentes poderão ser para ajudar se usadas adequadamente?

O livro recebeu as melhores referências da comunidade acadêmica: um trabalho que "ilumina", na expressão de outra veterana desse campo, Renée Fox, ou, como escreve Phil Brown, "uma fascinante combinação de história institucional e experiência pessoal. Sentimos como se estivéssemos nas salas das universidades, hospitais, escolas médicas e, agências governamentais onde estudos fundamentais foram realizados e novos programas iniciados".

\section{Referências}

BLOOM, S. W. The doctor and his patient: a sociological interpretation. New York: Russell Sage Foundation, 1963.

. Episodes in the institutionalization of medical sociology: a personal view. Journal of Health and Social Behavior, n. 31, p. 1-10, 1990.

. The intellectual in a time of crisis: the case of Bernhard J. Stern 18941956. Journal of the History of the Behavioral Sciences, n. 26, p. 17-37, 1990b. . Word as scalpel: a history of medical sociology. New York: Oxford University Press, 2002.

NUNES, E. D. A Sra. Tomasetti, Bloom e um projeto de ensino pioneiro. Ciência e Saúde Coletiva, v. 8, n. 1, p. 287-297, 2003.

PARSONS, T. The social system. Glencoe: The Free Press, 1951.

\section{NOTA}

- Doutor em Ciências, professor associado de Ciências Sociais em Saúde e Saúde Coletiva no Departamento de Medicina Preventiva e Social da Faculdade de Ciências Médicas da Unicamp. Endereço eletrônico: evernunes@uol.com.br. 